\title{
Complications and mortality of surgical therapy for esophageal cancer: 10 years single center experience
}

\author{
R. VRBA ${ }^{1}$, D. VRANA ${ }^{2, *}$, C. NEORAL ${ }^{1}$, R. AUJESKY ${ }^{1}$, M. STASEK ${ }^{1}$, T. BOHANES ${ }^{1}$, J. TESARIKOVA ${ }^{1}$, J. CINCIBUCH ${ }^{2}$, B. MELICHAR ${ }^{2}$, M. HORAKOVA ${ }^{3}$, \\ J. ZAPLETALOVA ${ }^{4}$
}

${ }^{1}$ First Department of Surgery, Faculty of Medicine and Dentistry and University Hospital Olomouc, Czech Republic; ${ }^{2}$ Department of Oncology, Faculty of Medicine and Dentistry and University Hospital Olomouc, Czech Republic; ${ }^{3}$ Department of Surgical Intensive Care, Faculty of Medicine and Dentistry and University Hospital Olomouc, Czech Republic; ${ }^{4}$ Department of Biophysics, Faculty of Medicine and Dentistry, Palacky University Olomouc, Czech Republic

${ }^{*}$ Correspondence: davvrana@gmail.com

Received October 13, 2017 / Accepted December 20, 2017

\begin{abstract}
This study presents a single-center retrospective study into complications and mortality in the surgical treatment of esophageal cancer between 2006 and 2015. A total of 212 patients with esophageal cancer were operated on at the First Department of Surgery University Hospital in Olomouc in The Czech Republic during this period. Adenocarcinoma was histologically described in 127 patients (59.9\%), squamous cell carcinoma in 82 patients (38.7\%) and other carcinoma types were described in the remaining 3 patients. The pre-operative staging of esophageal cancer established that patients with early stage disease (T1-2N0M0) had primary surgery and those with advanced stage (T3-4N0-2M0) were treated with neo-adjuvant chemoradiation before surgery. The following surgery was performed; trans-hiatal laparoscopic esophagectomy for 183 patients; Orringer esophagectomy in 4 patients; thoracoscopic esophagectomy in 17 patients and thoracotomy in 30 patients. Respiratory failure with the development of ARDS syndrome and multiple-organ failure occurred in 21 patients. Statistically significant associations between mortality and ASA $(\mathrm{p}=0.009)$ and respiratory complications and ASA $(\mathrm{p}=0.006)$ were demonstrated. The majority of patients who died were under 60 years of age $(\mathrm{p}=0.039)$ and there was significant association between 30-day mortality and tumor stage $(\mathrm{p}=0.021)$, gender $(\mathrm{p}=0.022)$ and age $(\mathrm{p}=0.018)$. A significant association was also identified between tumor stage and fistula in anastomosis, $(p=0.043)$ and the study convincingly established that esophagectomy should be performed in specialized high-volume centers experienced in treatment of this serious malignancy and only by certified oncology surgeons with long-term experience in esophageal surgery.
\end{abstract}

Key words: esophageal cancer, surgery, radiotherapy

The incidence of esophageal cancer has been increasing globally in recent decades. Its incidence in The Czech Republic has reached 3.38/100,000 and the mortality rate in 2012 was $2.43 / 100,000$. In $99 \%$ of cases, esophageal cancer consists of two principal histological types: squamous cell carcinoma in the upper and middle third of the esophagus, and adenocarcinoma of the distal esophagus; usually developing from the pre-cancerous condition of Barrett's esophagus. The prevalence of adenocarcinoma is increasing in developed countries in contrast to the 'esophageal belt' countries where the ratio of squamous cell carcinoma to adenocarcinoma is $60: 40 \%$. Radical esophagetomy is the only potentially curative therapy in most cases of esophageal cancer [1], and surgery is the primary treatment in the early disease stages unsuitable to endoscopic treatment. The treatment protocol in advanced cancer consists of neo-adjuvant chemoradiation followed by surgery. The aim of the surgical therapy is to remove the entire esophageal tumor and local regional nodes by lymphadenectomy [2].

\section{Patients and methods}

Patient population. Single center results of surgical treatment in patients with esophageal cancer between 2006 and 2015 were retrospectively analysed, and the following associations were assessed; the association of mortality, respiratory complications and occurrence of fistula in anastomosis was compared in gender, age (under and over 60 years), histology (adenocarcinoma and squamous cell carcinoma), neoadjuvant therapy (chemoradiation), American Surgical Association (ASA) score, the type of surgical procedure (transhiatal or transthoracic esophagectomy) and the disease stage. 
Staging procedures. Esophageal cancer was diagnosed by endoscopic examination including biopsy, endosonographic examination and positron emission tomography/computed tomography (PET-CT) scan. Endosonographic examination was performed selectively in patients with endoscopically permeable tumor. When the tumor was localized in the oral part of the esophagus, up to $30 \mathrm{~cm}$ from the incisors, tracheobronchoscopy was performed to evaluate the infiltration of the tracheo-bronchial tree. All patients had undergone general internal, spirometric and nutritional examinations before surgery was performed, and those with a history of cardiac disorder also underwent cardiologic evaluation, including echocardiography.

Patients were assessed on the results of these examinations and according to ASA physical status classification and microbiological examination of patient sputum and throat culture was consistently performed seven days before surgery to avoid respiratory infection. In case of lower respiratory tract infection, patients were treated with targeted antibiotic therapy and surgery was postponed. Even a minimal level of sputum contamination by infectious agents led to administration of targeted antibiotic prophylaxis, based on the microbial cultivation. Pre-operative esophageal cancer staging enabled patients with TNM-classified early stage disease (T1-2N0M0) to undergo primary surgery. Patients with advanced stage disease (T3-4N0-2M0) and no evidence of metastatic spread were indicated for neoadjuvant therapy. Feeding jejunostomy using the Witzel technique was introduced in patients with stenotizing tumor prior to the neoadjuvant therapy.

Neoadjuvant treatment. The neoadjuvant therapy consisted of three cycles of chemotherapy (5-fluorouracil and cisplatin) and radiotherapy (50 Gy in 2 Gy fractions). The restaging after neoadjuvant therapy (PET-CT examination and endoscopy) contributed to the definitive decision concerning surgical therapy within 8 to 12 weeks of the end of this treatment. Surgical procedure was contraindicated in patients with progressive disease or confirmed systemic metastases.

Surgical procedure. Esophagectomy was performed either by a hybrid approach combining minimally invasive therapy and open surgery or by the open technique. Transhiatal minimally invasive esophagectomy was indicated in patients with aboral tumor localization. The Orringer's esophagectomy technique was used only rarely where there was previous surgery of the gastroesophageal junction or when a minimally invasive approach was contraindicated because of internal co-morbidity. The transthoracic approach was selected if the tumor in the thoracic esophagus was localized up to $30 \mathrm{~cm}$ from the incisors. A minimally invasive thoracoscopic approach was preferred, but right-sided thoracotomy was primarily performed in patients with bulky tumors of the oral and the middle third of esophagus, with preoperative suspicion of infiltration of adjacent structures including the respiratory tract or aorta, and standard mediastinal lymph- adenectomy up to the tracheal bifurcation was performed in patients treated with transhiatal access. Total mediastinal lymphadenectomy was carried out in patients treated with the thoracotomy approach.

The reconstruction phase was performed by gastric conduit gastroplasty constructed by mini-laparotomy and cervical incision in the deep cervical space, but where gastroplasty could not be performed because of tumor infiltration of the esophagus and stomach, or previous gastric surgery, coloplasty was carried out. An extra-mucosal pyloromyotomy was performed in all patients. Where transhiatal minimally invasive procedure was indicated, the patients were operated under endotracheal anesthesia in supine position with abducted legs.

This operation was performed through five incisions, using 5 ports; four $10-\mathrm{mm}$ ports and one 5 -mm port. Laparoscope with 30-degree optics was introduced by a port inducted $5 \mathrm{~cm}$ above the umbilicus. The surgeon used the $10-\mathrm{mm}$ port on the left in the mid-axillary line, with the right hand manipulating a dissector with monopolar coagulation, harmonic scalpel and scissors, while the left hand worked in a 5-mm port with an Endo-clinch grasper introduced below the right costal arch, $5 \mathrm{~cm}$ from the linea alba. A further $10-\mathrm{mm}$ port under the breastbone enabled introduction of a retractor to elevate the left liver lobe. The last $10-\mathrm{mm}$ port below the left costal arch on the frontal axial line was designated for the atraumatic Babcock clamp.

After the lesser omentum was incised by harmonic scalpel and diaphragmatic crura were separated, the esophagus was gradually transhiatally separated from mediastinal pleura and released from the mediastinum up to the azygos vein, completing the lymphadenectomy. After this minimally invasive resection phase was completed, the esophagus was transected in the deep neck space from the left-sided cervical access and then resected by mini-laparotomy. The partly resected tubulised stomach with preserved blood supply from the right gastro-epiploic artery was predominantly used for esophageal replacement. Gastroplasty anastomosis to the cervical esophagus was constructed by single-layer continuous suture and transthoracic esophagectomy was performed from the right thoracoscopy in modified prone position using the selective intubation of the left bronchus with a collapsed right lung.

The following four incisions for $10-\mathrm{mm}$ ports were used; the camera port was placed in the posterior axillary line in the 5th intercostal space; the surgeon used the ports in the scapular and mid-axillary line in the 7th intercostal space and the last auxiliary port was located in the scapular line in the 3rd intercostal space. The surgeon was using the harmonic scalpel with his right hand and the dissector with his left while the assistant held the 30-degree optics and retractor for the collapsed lung.

After the dissection of the mediastinal pleura, the azygos vein was transected by vascular endostapler, the entire thoracic esophagus was removed and the chest tube was 
inserted. The open thoracic approach was carried out from the right thoracotomy in the 5th or 6th intercostal space. After dissection of the mediastinal pleura and exclusion of tumorous infiltration of the respiratory tract or aorta, the extirpation of the esophagus with mediastinal lymphadenectomy was performed, followed by chest tube and closure of the thoracotomy by individual anatomical layers.

The subsequent reconstruction phase was performed in the supine position in the identical way to that in the trans-hiatal esophagectomy. After the surgery, patients were hospitalized in intensive care and nutrition was provided by combined parenteral and enteral approach via biluminal nasojejunal tube. The barium swallow was performed on the 7th post-operative day in order to explore an anastomotic leak and the findings on gastroplasty or coloplasty. Finally, further gradual re-alimentation was reinstituted for favourable results.

Statistical analysis. The statistical data evaluation used statistical software SPSS Statistics, version 22. Fisher's exact test determined the association of categorical parameters and mortality and respiratory complications and anastomotic fistula. The Kruskal-Wallis and Mann-Whitney U tests then investigated associations between the number of removed lymph nodes and tumor type and the type of the procedure, respectively. The significance level of the tests was 0.05 .

\section{Results}

Surgical outcome. A total of 212 patients with esophageal cancer were operated on between January 2006 and December 2015. The histology identified adenocarcinoma in 127 patients (59.9\%), squamous cell carcinoma in 82 (38.7\%), and small-cell carcinoma, mucinous carcinoma and adenosquamous cell carcinoma in the remaining three. Primary surgery was performed in 46 patients $(21.7 \%)$ with early tumors (T1-2N0M0) and neo-adjuvant therapy was indicated in the 166 patients (78.3\%) with more advanced disease stage (T3-4N0-2M0). There were also the following divisions: trans-hiatal laparoscopic esophagectomy was performed in 156 patients; Orringer esophagectomy in 4; thoracoscopy-assisted esophagectomy in 17 and thoracotomy in 30 (Table 1). Tubulised stomach was used as a conduit in 208 patients and coloplasty was used in the remaining 4 .

The resection phase of the procedure was always completed in the minimally invasive way using transhiatal access, while conversion to thoracotomy was carried out in 7 patients with thoraco-scopic access. The reason for the conversion was a bulky esophageal tumor and impossibility to assess loco-regional operability of the cancer using the minimally invasive approach. The median operation time was 214 minutes in transhiatal access, 237 minutes in thoraco-scopic surgeries and 275 minutes in thoracotomy. The average total blood loss in operated patients was $760 \mathrm{ml}$, thus requiring blood transfusions in 138 patients either peri or post-operatively. Lymphadenectomy was performed with average retrieval of 17.3 lymph nodes and the average hospital stay was 24.9 days. Based on histological examination of the tissue specimen, staging of esophageal cancer was evaluated according to the 2009 TNM classification (Table 1).

Surgical complications. Perioperative complications included massive bleeding from the aorta in 3 bulky mid-esophageal tumors which infiltrated the wall of the aorta, and two cases of bleeding from the vena cava in patients treated with transhiatal access. Bleeding was treated by $5 / 0$ prolene suture. Major airway injuries were repaired by absorbable suture 2/0: in the trachea in 2 patients and the left bronchus in 3. Opening of one or both pleural cavities was observed in 109 patients with transhiatal laparoscopic esophagectomies. This was treated by chest tube with active suction.

Respiratory complications presented the most important impacts on post-operative morbidity and mortality, with respiratory failure, development of adult respiratory distress

Table 1. Characteristics of the group of patients operated for esophageal cancer at the $1^{\text {st }}$ Surgical Department.

\begin{tabular}{lll}
\hline Total number of patients with esophageal cancer & $\mathbf{2 1 2}$ & $\%$ \\
\hline Male/Female & $183 / 29$ & $86.3 / 13.7 \%$ \\
60 and under years/Above 60 years & $105 / 107$ & $49.5 / 50.5 \%$ \\
Squamous cell carcinoma & 81 & $38.2 \%$ \\
Adenocarcinoma & 126 & $59.4 \%$ \\
Other carcinomas & 3 & $1.4 \%$ \\
neoadjuvant therapy & 166 & $78.3 \%$ \\
ASA I,II,III,IV,V & $7,97,108,0,0$ & $3.3 \%, 45.8 \%, 50.9 \%, 0 \%, 0 \%$ \\
Transhiatal minimally invasive esophagectomy & 156 & $73.6 \%$ \\
Transthoracic minimally invasive esophagectomy & 35 & $16.5 \%$ \\
Standard transhiatal esophagectomy & 4 & $1.9 \%$ \\
Standard transthoracic esophagectomy & 17 & $8.0 \%$ \\
Respiratory complications & 77 & $36.3 \%$ \\
fistula in anastomosis & 19 & $8.9 \%$ \\
30-day-mortality & 12 & $5.7 \%$ \\
90-day-mortality & 4 & $1.9 \%$ \\
\hline
\end{tabular}


syndrome (ARDS) and possible development of multiple organ failure reported in 21 patients. Comprehensive therapy including artificial ventilation, tracheostomy, bronchoscopic toilette and antibiotic therapy was successful in 8 of these patients. Less serious respiratory complications including pneumonia, pleural effusion, and post-operative pneumothorax were observed in 56 patients. These complications were treated with targeted antibiotic therapy for pneumonia and pleural cavity complications (fluidothorax, empyema, or pneumothorax) were treated by targeted drainage. Chylothorax was detected in 6 patients and surgical ligation of the thoracic duct was performed in 2 patients after the failure of conservative therapy for chylothorax.

Cardiac complications mostly included temporary arrhythmias, with sinus tachycardia or atrial fibrillation in 21 patients who were treated with medical success. An extensive myocardial infarction on the third postoperative day was the cause of death in one patient and the most serious surgical complication was necrotic gastroplasty in one patient. Here, the gastroplasty was extirpated and cervical esophagostomy and nutritional jejunostomy were constructed with subsequent drainage of the mediastinum and abdominal cavity. However, the patient died due to severe shock and multiple organ failure on the 28th post-operative day.

Fistula in the cervical anastomosis occurred in 19 patients. Seven patients were treated for severe dehiscence and sepsis by surgical revision with drainage and antibiotic therapy. Asymptomatic fistula was detected in 17 patients by barium swallow, and here enteral and parenteral nutrition was continued. Persistent fistulas in two patients were treated with biodegradable stent and the fistula between the trachea and gastric conduit observed in 2 patients were treated by implantation of a biodegradable stent in the neo-esophagus. The fistulae healed after the stent implantation in all cases.

Examination of symptomatic hoarseness by phoniatrics proved left recurrent nerve palsy in 19 patients, but the palsy gradually subsided after phoniatric rehabilitation and conservative anti-edematous and inhalation therapy in 10 of these patients. Complications were evaluated according to the Clavien-Dindo classification of surgical complications

Table 2. Assessment of the group of patients according to the ClavienDindo classification of surgical complications.

\begin{tabular}{lcc}
\hline $\begin{array}{l}\text { Clavien-Dindo Classification } \\
\text { of Surgical Complications }\end{array}$ & number & $\%$ \\
\hline 0 & 47 & $22.2 \%$ \\
1 & 27 & $12.7 \%$ \\
2 & 68 & $32.1 \%$ \\
$3 \mathrm{a}$ & 24 & $11.3 \%$ \\
$3 \mathrm{~b}$ & 8 & $3.8 \%$ \\
$4 \mathrm{a}$ & 15 & $7.1 \%$ \\
$4 \mathrm{~b}$ & 7 & $3.3 \%$ \\
5 & 16 & $7.5 \%$ \\
\hline
\end{tabular}

(Table 2). The thirty-day mortality of the patient cohort was $5.7 \%$ (12 patients; with respiratory complications in 9 cases and myocardial infarction, and necrosis of the gastroplasty in one case each) and ninety-day mortality added 1.9\% (4 patients with multiple organ failure in ARDS) - (Table 3).

Statistical analysis of the evaluated factors demonstrated significant correlation between mortality and ASA score $(\mathrm{p}=0.009)$ and respiratory complications and ASA score $(\mathrm{p}=0.006)$ (Table 4). Patients classified with an ASA score of 3 had significantly higher risk of post-operative death and respiratory complications. Significantly more patients aged over 60 years were among those who died post-operatively $(p=0.039)$ and significant associations between the 30-day mortality and tumor stage $(\mathrm{p}=0.021)$, gender $(\mathrm{p}=0.022)$ and age $(\mathrm{p}=0.018)$ were also more evident in women and patients aged over 60 years. The association between the 90-day mortality and ASA score $(\mathrm{p}=0.002)$ was also demonstrated with a significantly higher number of patients classified with ASA score of 3 among those who died. Anastomotic leak was significantly associated with tumor stage $(\mathrm{p}=0.043)$; with increased stage IV disease in the group, but no significant associations were noted between the number of lymph nodes removed by transhiatal and transthoracic access and the tumor type ( $\mathrm{p}=0.725)$, or between the number of removed lymph nodes and the type of procedure $(\mathrm{p}=0.879)$.

\section{Discussion}

Esophagectomy is the only curative therapy for esophageal cancer. The intervention can be performed by an open surgical approach, a hybrid technique combining conventional and minimally invasive surgery or by a completely minimally invasive approach [3]. The literature indicates that the currently preferred approach in most centers is the minimally invasive approach during the resection operation phase, and combined with the conventional approach in reconstruction of the upper gastrointestinal tract [4.5].

In distal tumors (30 $\mathrm{cm}$ from the incisors and lower), the operation is performed by transhiatal access without planned thoracotomy. The operation begins with laparoscopic transhiatal access. The esophagus is then released from the mediastinum above the tumor. The passage is mostly restored by tubulized stomach in the form of gastroplasty, with the anastomosis constructed on the stump of the cervical esophagus in the deep neck space. A perfect visualization of the operative field, enabling selective hemostasis and the performance of mediastinal lymphadenectomy reaching the bifurcation of the trachea, is considered the principal benefit of this approach.

Esophagectomy of tumors located in the oral and middle part of the esophagus is most frequently performed through the right-sided transthoracic access with chest or neck anastomosis. We prefer thoracoscopic access when the tumor is in this location, but right-sided thoracotomy is indicated for large tumors, in possible tumor adherence or even partial 
Table 3. Statistically assessed mortality of the group of patients with esophageal cancer.

\begin{tabular}{|c|c|c|c|c|c|c|}
\hline & & \multicolumn{2}{|c|}{$\begin{array}{c}\text { Survived } \\
(\mathrm{n}=196)\end{array}$} & \multicolumn{2}{|c|}{$\begin{array}{c}\text { Died } \\
(n=16)\end{array}$} & \multirow{2}{*}{$\begin{array}{c}\text { Fisher's exact test } \\
\text { p-value }\end{array}$} \\
\hline & & Number & $\%$ & Number & $\%$ & \\
\hline \multirow[t]{3}{*}{ Carcinoma Type } & Adenocarcinoma & 119 & $60.8 \%$ & 8 & $50.0 \%$ & \multirow{3}{*}{0.614} \\
\hline & Squamous cell carcinoma & 74 & $37.8 \%$ & 8 & $50.0 \%$ & \\
\hline & Other & 3 & $1.4 \%$ & 0 & $0.0 \%$ & \\
\hline \multirow[t]{3}{*}{ ASA } & 1 & 7 & $3.6 \%$ & 0 & $0.0 \%$ & \multirow{3}{*}{0.009} \\
\hline & 2 & 95 & $48.5 \%$ & 2 & $12.5 \%$ & \\
\hline & 3 & 94 & $48.0 \%$ & 14 & $87.5 \%$ & \\
\hline \multirow[t]{4}{*}{ Procedure Type } & THL & 144 & $73.5 \%$ & 12 & $75.0 \%$ & \multirow{4}{*}{0.551} \\
\hline & THK & 4 & $2.0 \%$ & 0 & $0.0 \%$ & \\
\hline & TTM & 31 & $15.8 \%$ & 4 & $25.0 \%$ & \\
\hline & TTK & 17 & $8.7 \%$ & 0 & $0.0 \%$ & \\
\hline \multirow[t]{2}{*}{ Neoadjuvant therapy } & no & 43 & $21.9 \%$ & 3 & $18.8 \%$ & \multirow{2}{*}{1} \\
\hline & yes & 153 & $78.1 \%$ & 13 & $81.3 \%$ & \\
\hline \multirow[t]{9}{*}{ Surgical staging } & CR & 30 & $15.3 \%$ & 1 & $6.3 \%$ & \multirow{9}{*}{0.263} \\
\hline & I.A & 20 & $10.2 \%$ & 1 & $6.3 \%$ & \\
\hline & I.B & 26 & $13.3 \%$ & 0 & $0.0 \%$ & \\
\hline & II.A & 37 & $18.9 \%$ & 4 & $25.0 \%$ & \\
\hline & II.B & 22 & $11.2 \%$ & 1 & $6.3 \%$ & \\
\hline & III.A & 24 & $12.2 \%$ & 2 & $12.5 \%$ & \\
\hline & III.B & 17 & $8.7 \%$ & 3 & $18.8 \%$ & \\
\hline & III.C & 17 & $8.7 \%$ & 3 & $18.8 \%$ & \\
\hline & IV. & 3 & $1.5 \%$ & 1 & $6.3 \%$ & \\
\hline \multirow[t]{2}{*}{ Gender } & male & 171 & $87.2 \%$ & 12 & $75.0 \%$ & \multirow{2}{*}{0.245} \\
\hline & female & 25 & $12.8 \%$ & 4 & $25.0 \%$ & \\
\hline \multirow[t]{2}{*}{ Over 60 years } & no & 93 & $47.4 \%$ & 12 & $75.0 \%$ & \multirow{2}{*}{0.039} \\
\hline & yes & 103 & $52.6 \%$ & 4 & $25.0 \%$ & \\
\hline
\end{tabular}

Significant association between mortality and ASA was found ( $\mathrm{p}=0.009)$, significantly more patients who died had ASA 3 . Furthermore, it was shown that in the group of patients who died, significantly more patients were under the age of $60(\mathrm{p}=0.039)$.

infiltration of the tumor into the major airways discovered in the pre-operative staging which includes EUS or PET/CT. The goal of the thoracotomy is to evaluate the operability of the tumor and to avoid severe injury to the respiratory tract where initial tumor infiltration is found. In contrast to the transhiatal approach, transthoracic access allows extended mediastinal lymphadenectomy. Chen et al. reported worse long-term outcomes of the three-field lymphadenectomy (neck, mediastinal and celiac lymph nodes) in patients with higher $\mathrm{T}$ stage and age over 60 years than in the intrathoracic approach [6].

The number of metastatic lymph nodes is considered an independent prognostic factor predicting the outcome of surgical therapy in esophageal cancer [7]. Lymphadenectomy for esophageal cancer should contain at least 15 removed nodes. Bollschweiller et al. reported significantly longer survival after resection of the esophagus in patients with at least 15 negative lymph nodes compared to patients with fewer than 15 [8]. The reconstruction phase in both types is carried out by mini-laparotomy and cervical incision. Anastomosis can be constructed in the deep neck space or intrathoracically while maintaining the principles of oncological radicality of the procedure, and it can be constructed manually, stapled or as a semi-mechanical anastomosis.

Extramucosal pyloromyotomy was performed in all patients undergoing esophagectomy in order to eliminate gastric outlet obstruction from pylorospasm caused by resection of both vagal nerves. Peri-operative complications including bleeding and injury to surrounding structures, such as the respiratory tract, blood vessels and abdominal organs, are dealt with surgically during the operation.

Respiratory complications are the most serious met in the post-operative course, and these most affect patient post-esophagectomy mortality. The incidence of respiratory complications following esophagectomy is reportedly between 19 and 44\% [9, 10]. However, the literature provides no unanimous opinion on their occurrence in minimally invasive and open approaches. Some authors describe a lower incidence of respiratory complications in the minimally invasive approach, but others report respiratory complication incidence is comparable in minimally invasive esophagectomy and traditional approaches [11]. The present experience herein established a lower incidence of respiratory complications in patients with minimally invasive 
Table 4. Statistical evaluation of respiratory complications in patients with esophageal cancer.

\begin{tabular}{|c|c|c|c|c|c|c|}
\hline & & \multicolumn{2}{|c|}{$\begin{array}{l}\text { No respiratory complications } \\
\qquad(\mathrm{n}=135)\end{array}$} & \multicolumn{2}{|c|}{$\begin{array}{c}\text { Respiratory complications } \\
(\mathbf{n}=77)\end{array}$} & \multirow{2}{*}{$\begin{array}{c}\text { Fisher's exact test } \\
\text { p-value }\end{array}$} \\
\hline & & Number & $\%$ & Number & $\%$ & \\
\hline \multirow[t]{3}{*}{ Carcinoma type } & adenocarcinoma & 86 & $63.7 \%$ & 41 & $53.2 \%$ & \multirow{3}{*}{0.240} \\
\hline & Squamous cell carcinoma & 47 & $34.8 \%$ & 35 & $45.5 \%$ & \\
\hline & other & 2 & $1.5 \%$ & 1 & $1.3 \%$ & \\
\hline \multirow[t]{3}{*}{ ASA } & 1 & 5 & $3.7 \%$ & 2 & $2.6 \%$ & \multirow{3}{*}{0.006} \\
\hline & 2 & 72 & $53.3 \%$ & 25 & $32.5 \%$ & \\
\hline & 3 & 58 & $43.0 \%$ & 50 & $64.9 \%$ & \\
\hline \multirow[t]{5}{*}{ Procedure Type } & THL & 98 & $72.6 \%$ & 58 & $75.3 \%$ & \multirow{5}{*}{0.607} \\
\hline & THK & 4 & $3.0 \%$ & 0 & $0.0 \%$ & \\
\hline & TTM & 22 & $16.3 \%$ & 13 & $16.9 \%$ & \\
\hline & TTK & 11 & $8.1 \%$ & 6 & $7.8 \%$ & \\
\hline & thoracic & 33 & $24.4 \%$ & 19 & $24.7 \%$ & \\
\hline \multirow[t]{2}{*}{ Neoadjuvant therapy } & no & 29 & $21.5 \%$ & 17 & $22.1 \%$ & \multirow{2}{*}{1} \\
\hline & yes & 106 & $78.5 \%$ & 60 & $77.9 \%$ & \\
\hline \multirow[t]{9}{*}{ Pathological stage } & $\mathrm{pCR}$ & 20 & $14.8 \%$ & 11 & $14.3 \%$ & \multirow{9}{*}{0.718} \\
\hline & I. A & 12 & $8.9 \%$ & 9 & $11.7 \%$ & \\
\hline & I. B & 13 & $9.6 \%$ & 13 & $16.9 \%$ & \\
\hline & II. A & 29 & $21.5 \%$ & 12 & $15.6 \%$ & \\
\hline & II. B & 16 & $11.9 \%$ & 7 & $9.1 \%$ & \\
\hline & III. A & 19 & $14.1 \%$ & 7 & $9.1 \%$ & \\
\hline & III. B & 12 & $8.9 \%$ & 8 & $10.4 \%$ & \\
\hline & III. C & 12 & $8.9 \%$ & 8 & $10.4 \%$ & \\
\hline & IV. & 2 & $1.5 \%$ & 2 & $2.6 \%$ & \\
\hline \multirow[t]{2}{*}{ gender } & male & 117 & $86.7 \%$ & 66 & $85.7 \%$ & \multirow{2}{*}{0.838} \\
\hline & female & 18 & $13.3 \%$ & 11 & $14.3 \%$ & \\
\hline Age Over 60 years & no & 63 & $46.7 \%$ & 42 & $54.5 \%$ & 0.318 \\
\hline
\end{tabular}

Significant dependence was observed between the incidence of respiratory complications and ASA ( $\mathrm{p}=0.006)$. In the group of patients with respiratory complications, significantly more ASA 3 patients were present.

transhiatal laparoscopic esophagectomy than after the open thoracotomy procedure [12]. Here, all patients had sputum microbiological examination and a throat culture taken 7 days before the planned surgery to prevent the occurrence of respiratory complications. Individualized prophylaxis was then dependent on these results and if there was a high level of microbial contamination the patients were treated with antibiotics and surgery was postponed [13]. An 11\% decrease in the incidence of respiratory complications has been obtained in the last 3 years due to targeted antibiotic prophylaxis and therapy.

Necrosis of the gastro/coloplasty due to inadvertent perfusion of the conduit is considered the mostly fatal postoperative complication. This is more frequently described in coloplasty ( $13.3 \%$ of patients) than in gastroplasty $(0.5 \%)$ [14]. Whooley et al. reported gastro/coloplasty necrosis in $0.8 \%$ of patients in a cohort of 710 patients operated for esophageal cancer [15]. Possible decrease can be achieved by ICG validation of the gastric conduit perfusion.

Literary evidence describes the incidence of anastomotic dehiscence in 5 to $20 \%$ of patients $[16,17]$. The leakage risk factors include all the following; age, male gender, smoking, alcohol abuse, ASA score, prolonged operation time, low serum albumin concentration, intraoperative blood loss, diabetes, kidney failure and cardiovascular disease [18, 19]. Dehiscence occurs more commonly in cervical anastomoses than in thoracic anastomoses, but the occurrence of thoracic leak portends $60 \%$ mortality with the development of mediastinitis and multiple organ failure in septic shock [20].

Other typical esophagectomy complications include recurrent laryngeal nerve palsy; with incidence ranging from 7 to $30 \%$. The incidence of recurrent nerve palsy and anastomotic dehiscence is higher in patients treated with cervical access [21]. In addition, injury to the thoracic duct may gradually lead to the development of chylothorax. If the conservative management of chylothorax fails, surgical revision is indicated with direct ligation of the injured thoracic duct. Surgical site infections also add to these complications; and abscess formation in the abdominal cavity, inflammatory fluidothorax and even empyema of the thoracic cavity are all treated by CT guided drainage.

There is general consensus in the literature recommending the performance of esophagectomy in centers specialized in esophageal cancer surgery, where the type of procedure 
performed agrees with the philosophy of that particular department [22]. Therefore, esophagectomy should definitely be performed in specialized high-volume centers with experience in treatment of this serious malignancy and performed by a certified surgical oncologist who has long-term experience in esophageal cancer surgery [23, 24]. Further research is also required to identify potential prognostic and predictive factors for esophageal cancer treatment outcome and patient survival $[25,26]$.

In conclusion, esophageal cancer is a serious malignant disease requiring esophagectomy as a fundamental part of radical treatment. From a surgical standpoint, esophagectomy with lymphadenectomy is a demanding procedure. The reconstructive phase involves replacement of the removed esophagus using a tubulized stomach as gastroplasty or the colon as coloplasty. The outcomes of the open and hybrid minimally invasive approach are comparable. In specialized centers, multidisciplinary collaboration of highly experienced specialists involved in esophageal cancer therapy is a fundamental principle of the treatment protocol. Finally, the best possible surgical outcomes of this serious malignancy can be achieved only when all these elementary conditions are met.

\section{References}

[1] KUTUP A, NENTWICH MF, BOLLSCHWEILER E, BOGOEVSKI D, IZBICKI JR et al. What should be the gold standard for the surgical component in the treatment of locally advanced esophageal cancer: transthoracic versus transhiatal esophagectomy. Ann Surg 2014; 260: 1016-1022. https://doi.org/10.1097/SLA.0000000000000335

[2] NINOMIYA I, OSUGI H, FUJIMURA T, FUSHIDA S, OKAMOTO K et al. Thoracoscopic esophagectomy with extended lymph node dissection in the left lateral position: technical feasibility and oncologic outcomes. Dis Esophagus 2014; 27: 159-167. https://doi.org/10.1111/dote.12071

[3] MENG F, LI Y, MA H, YAN M, ZHANG R. Comparison of outcomes of open and minimally invasive esophagectomy in 183 patients with cancer. J Thorac Dis 2014; 6: 1218-1224. https://doi.org/10.3978/j.issn.2072-1439.2014.07.20

[4] ZHAI C, LIU Y, LI W, XU T, YANG G et al. A comparison of short-term outcomes between Ivor-Lewis and McKeown minimally invasive esophagectomy. J Thorac Dis 2015; 7: 2352-2358. https://doi.org/10.3978/j.issn.20721439.2015.12.15

[5] BIERE SS, VAN BERGE HENEGOUWEN MI, MAAS KW, BONAVINA L, ROSMAN C et al. Minimally invasive versus open oesophagectomy for patients with oesophageal cancer: a multicentre, open-label,randomised controlled trial. Lancet 2012; 379: 1887-1892. https://doi.org/10.1016/S01406736(12)60516-9

[6] CHEN X, CHEN J, ZHENG X, CHEN Y, LIN Y et al. Prognostic factors in patients with thoracic esophageal carcinoma staged pT1-4aN0M0 undergone esophagectomy with three-field lymphadenectomy. Ann Transl Med 2015; 3: 282. https://doi.org/10.3978/j.issn.2305-5839.2015.11.05
[7] CHEN J, PAN J, ZHENG X, ZHU K, LI J et al. Number and location of positive nodes, postoperative radiotherapy, and survival after esophagectomy with three-field lymph node dissection for thoracic esophageal squamous cell carcinoma. Int J Radiat Oncol Biol Phys 2012; 82: 475-482. https://doi. org/10.1016/j.ijrobp.2010.08.037

[8] BOLLSCHWEILER E, BALDUS SE, SCHRODER W, SCHNEIDER PM, HOLSCHER AH. Staging of esophageal carcinoma: length of tumor and number of involved regionallymph nodes. Are these independent prognostic factors? J Surg Oncol 2006; 94: 355-363. https://doi.org/10.1002/jso.20569

[9] OTT K, BADER FG, LORDICK F, FEITH M, BARTELS H et al. Surgical factors influence the outcome after Ivor-Lewis esophagectomy with intrathoracic anastomosis for adenocarcinoma of the esophagogastric junction: a consecutive series of 240 patient at an experienced center. Ann Surg Oncol 2009; 16: 1017-1025. https://doi.org/10.1245/s10434-009-0336-5

[10] FERGUSON MK, DURKIN AE. Preoperative prediction of the risk of pulmonary complications after esophagectomy for cancer. J Thorax Cardiovasc Surg 2002; 123: 661-669.

[11] DECKER G, COOSEMANS W, DE LEYN P, DECALUWE $\mathrm{H}, \mathrm{NAFTEUX} \mathrm{P}$ et al. Minimally invasive esophagestomy for cancer. Eur J Cardiothorax Surg 2009; 35: 13-20. https://doi. org/10.1016/j.ejcts.2008.09.024

[12] AUJESKY R, NEORAL C, KRAL V, BOHANES T, VRBA R et al. Video-assisted laparoscopic resection of the esofagus for carcinoma after neoadjuvant therapy. HepatoGastroenterology 2009; 56: 1035-1038.

[13] Horaková M, Lubušká L, Kolář K, Hricová K, Vrba R et al. Individualized prophylaxis in patients with esophageal replacement for cancer. Surg Infect (Larchmt) 2015; 16: 513517. https://doi.org/10.1089/sur.2014.132

[14] WORMUTH JK, HEITMILER RF. Esophageal conduit necrosis. J Thorac Surg Clin 2006; 16: 11-22. https://doi. org/10.1016/j.thorsurg.2006.01.003

[15] WHOOLY BP, LAW S, MURTHY SC, ALEXANDROU A, WONG J. Analysis of reduced death and complication rates after esophageal resection. Ann Surg 2001; 233: 338-344.

[16] SUNPAWERAVONG S, RUANGSIN S, LAOHAWIRIYAKAMOL S, MAHATTANOBON S, GEATER A. Prediction of major postoperative complications and survival forlocally advanced esophageal carcinoma patients. Asian J Surg 2012; 35: 104-109. https://doi.org/10.1016/j.asjsur.2012.04.029

[17] HAGA Y, WADA Y, TAKEUCHI H, IKEJIRI K, IKENAGA M. Prediction of anasto-motic leak and its prognosis in digestive surgery. World J Surg 2011; 35: 716-722. https://doi. org/10.1007/s00268-010-0922-5

[18] VAN DAELE E, VAN DE PUTTE D, CEELEN W, VAN NIEUWENHOVE Y, PATTYN P. Risk factors and consequences of anastomotic leakage after Ivor Lewis oesophagectomy. Interact Cardiovasc Thorac Surg 2016; 22: 32-37. https://doi.org/10.1093/icvts/ivv276

[19] KASSIS E, KOSINSKI A, ROSS P JR, KOPPENS K, DONAHUE J et al. Predictors of anastomotic leak after esophagectomy: an analysis of the society of thoracic surgeons general thoracic database. Ann Thorac Surg 2013; 96: 1919-1926. https://doi.org/10.1016/j.athoracsur.2013.07.119 
[20] URSEHEL JD. Esophagogastrostomy anastomotic leaks comlicating esophagectomy: a review. Am J Surg 1995; 169: 634-640.

[21] LUKETICH JD, PENNATHUR A, AWAIS O, LEVY RM, KEELEY $S$ et al. Outcomes after minimally invasive esophagectomy: review of over 1000 patients. Ann Surg 2012; 256: 95-103. https://doi.org/10.1097/SLA.0b013e3182590603

[22] MARIETTE C, TAILLIER G, VAN SEUNINGEN I, TRIBOULET JP. Factor affecting postoperative course and survival after en bloc resection for esophageal carcinoma. Ann Thorac Surg 2004; 78: 1177-1183. https://doi.org/10.1016/j. athoracsur.2004.02.068

[23] PENNATHUR A, AWAIS O, LUKETICH JD. Technique of minimally invasive Ivor Lewis esophagectomy. Ann Thorac Surg 2010; 89: S2159-2162. https://doi.org/10.1016/j.athoracsur.2010.03.069
[24] TAPIAS LF, MORSE CR. Minimally invasive Ivor Lewis esophagectomy: description of a learning curve. J Am Coll Surg 2014; 218: 1130-1140. https://doi.org/10.1016/j.jamcollsurg.2014.02.014

[25] VRANA D, MATZENAUER M, AUJESKY R, VRBA R, NEORAL $C$ et al. Potential Predictive Role of MicroRNAs in the Neoadjuvant Treatment of Esophageal Cancer. Anticancer Res 2017; 37: 403-412. https://doi.org/10.21873/anticanres. 11332

[26] VRANA D, HLAVAC V, BRYNYCHOVA V, VACLAVIKOVA R, NEORAL C et al. ABC Transporters and Their Role in the Neoadjuvant Treatment of Esophageal Cancer. Int J Mol Sci 2018; 19: pii: E868. https://doi.org/10.3390/ijms19030868 